\title{
Somatic Gene Transfer of NGF to the Aged Brain: Behavioral and Morphological Amelioration
}

\author{
Karen S. Chen ${ }^{1}$ and Fred H. Gage 2 \\ 'Department of Neurosciences, Genentech, Inc., South San Francisco, California 94080 and ${ }^{2}$ Department of \\ Neurosciences, Clinical Science Building, University of California at San Diego, La Jolla, California 92093-0627
}

\begin{abstract}
Primary fibroblasts modified to secrete nerve growth factor (NGF) were implanted into the nucleus basalis magnocellularis (NBM) of aged memory impaired rats. The NGF-producing fibroblasts survived for 6 weeks following transplantation and continued expressing NGF mRNA through the duration of the experiment. A significant amelioration of the memory impairment and a significant increase in size and number of low-affinity NGF receptor (p75)-positive neurons in the basal forebrain were observed. Implantation of NGF-producing cells into normal young adult rats resulted in a transient but significant memory impairment and hypertrophy of low-affinity NGF receptor-positive neurons. These results show that naturally occurring age-related memory loss can be reversed by grafting cells engineered to secrete NGF directly to the NBM, and that either cholinergic hyper- or hypofunction may lead to cognitive impairments.
\end{abstract}

[Key words: aging, NGF, learning, memory, cholinergic, neurotrophins, nucleus basalis magnocellularis, basal forebrain]

Gene transfer to the CNS can be used both to explore basic biological questions concerning the structure and function of the brain or as a form of somatic gene therapy (Gage et al., 1991). With this approach, cells are taken from the body, grown in vitro, transfected with a gene that makes molecules of functional importance, and implanted into the brain. A principal advantage of this approach is the local intraparenchymal delivery of factors to responsive cells, which allows one to examine the effects of the factors on specific populations of cells. Additionally, following the implantation of the transfected cells there is no need for any further invasive procedure, such as the chronic infusion of various factors into the cerebral ventricles by osmotic minipump.

Cells genetically engineered to secrete NGF and implanted into the brain were shown to prevent the degeneration of cholinergic neurons that normally occurs following axotomy (Ro-

\footnotetext{
Received June 16, 1994; revised Sept. 15, 1994; accepted Oct. 13, 1994.

We thank Dr. Heidi Phillips and Mark Armanini of Genentech for assisting in the in situ hybridization procedure and analysis. We thank Dr. Jaso Ray for construction of the NGF retrovirus and establishing the producer cells. We thank Regina Wu for conducting the NGF two-site ELISAs. We thank Drs. Lisa Fisher, Mark Tuszynski, Diane Swick, Marie-Claude Senut, Steve Minger and Mary Lynn Gage for helpful comments on the manuscript. We thank the Syntex-Synergen Collaboration for the human $\mathrm{cDN} \Lambda$ for nerve growth factor. This work was supported in part by the National Institute on Aging and the Herbert and Margaret Hoover Foundation.

Correspondence should be addressed to Fred H. Gage, UCSD, 7500 Gilman Drive, La Jolla, CA 92093-0627.

Copyright (C) 1995 Society for Neuroscience $0270-6474 / 95 / 152819-07 \$ 05.00 / 0$
}

senberg et al., 1988; Stromberg et al., 1990; Whittemore et al., 1991). These NGF-producing cellular implants have been shown to protect cholinergic neurons from dying and induce regeneration of the transected axons (Kawaja et al., 1992). Recently, Dekker et al. (1994) reported a significant behavioral improvement in rats implanted with NGF-producing fibroblasts after they had received bilateral excitotoxic lesions to the nucleus basalis. Intraperitoneal injections of cells genetically modified to secrete ciliary neurotrophic factor (CNTF) were able to prevent the degeneration of motor neurons in mutant mice with progressive motor neuron degeneration (Sendtner et al., 1992). Additionally, intracerebral implants of cells expressing NT-3 have been reported to support the survival of locus coeruleus cells (Arenas and Perrson, 1994). In the present experiment, we sought to determine if behavioral as well as morphological deficits could be reversed following implantation of NGF-producing cellular grafts into aged animals, as well as examining the effects of these grafts in young adult animals.

Chronic unilateral infusions of purified NGF into the lateral ventricles of cognitively impaired aged rats (Fischer et al., 1987, 1991; Williams et al., 1991; Markowska et al., 1994) resulted in a significant improvement in spatial memory and increase in markers of cholinergic function in the basal forebrain. Since the NGF was delivered to the lateral ventricle, it was not clear whether the behavioral and morphological effects were a result of NGF's action in the terminal fields of the cholinergic neurons, hippocampus, and frontal cortex, or directly on the cell bodies in the septum and nucleus basalis (NBM). The most robust morphological change was measured in the NBM; thus, in this experiment we bilaterally implanted cells engineered to secrete NGF into a region adjacent to the NBM in aged rats and tested the animals for their ability to remember a previously learned task. The behavioral and morphological effects of grafts of NGF-secreting cells implanted into the NBM of normal young adult rats were also assessed.

\section{Materials and Methods}

Cell culture and infections. Primary fibroblasts were obtained from abdominal skin biopsies of Fischer 344 rats. Rats were anesthetized with a mixture $(4 \mathrm{ml} / \mathrm{kg})$ of ketamine $(25 \mathrm{mg} / \mathrm{mll})$, rompun $(1.3 \mathrm{mg} / \mathrm{kg})$, and acepromazine $(0.25 \mathrm{mg} / \mathrm{ml})$. A $1-2 \mathrm{~cm}^{2}$ area of skin was removed, rinsed in alcohol, and placed into sterile DMEM/S. The biopsies were transfered to coverslips and grown in DMEM/S for $21 \mathrm{~d}$. The fibroblasts were then infected with murine retroviral vectors containing human $\beta$-NGF cDNA (provided by the Syntex-Synergen Collaboration) (for a more detailed description see Rosenberg et al., 1988). The vector also contained a dominant selectable marker, the transposon Tn5 neomycinresistant gene under the control of an internal Rous sarcoma virus promoter, which allowed selection of infected cells with the neomycin analog G418. The cells were maintained in standard culture conditions 
until grafting. An ELISA two-site immunoassay for NGF revealed that the primary fibroblasts genetically modified to produce NGF secreted approximately $172 \mathrm{pg} / \mathrm{hr} / 10^{5}$ cells into the culture medium. Thus, implanting $3 \times 10^{6}$ cells/side would yield $5.2 \mathrm{ng}$ of NGF per side per day. However, NGF secretion and number of surviving cells probably decreased during the course of the experiment.

Surgery. A subgroup of the behaviorally impaired aged rats $(n=12)$ and nonimpaired young adult rats $(n=8)$ were deeply anesthetized and received injections of either NGF-producing or noninfected primary skin fibroblasts. The cell suspensions were stereotaxically placed bilaterally dorsal to the nucleus basalis (injection coordinates: $A P=-3.5$ $\mathrm{mm}, \mathrm{MI},=+3.0 \mathrm{~mm}, \mathrm{DV}=-7.0 \mathrm{~mm}$ relative to bregma and +5.0 $\mathrm{mm}$ nose bar). A total of $1 \times 10^{5}$ cells $/ \mu$ l suspended in $3 \mu$ l of phosphate-buffered saline containing $1 \mu \mathrm{g} / \mu \mathrm{l} \mathrm{MgCl}_{2}$ and $\mathrm{CaCl}_{2}$ and $0.1 \%$ glucose was injected per site. Each injection was performed over a period of $3 \mathrm{~min}$, and the injection needle remained in place for an additional minute following completion of the injection. The scalp was then closed, and the animal was returned to its home cage.

Behavioral testing. Aged ( 24 month) $(n=18)$ and young adult ( 3 month) $(n=14)$ female Fischer 344 rats were tested in a Morris water maze. Rats were given four consecutive trials per day starting from four different pseudorandomized start locations with a $20 \mathrm{sec}$ intertrial interval and a $90 \mathrm{sec}$ maximum swim latency per trial. Data collection was automated by a computerized video tracking system (San Diego Instruments). The total swim distance, the percentage of swim distance spent in the platform quadrant, and the latency to find the platform were analyzed. The correlation between each of these variables was greater than $90 \%$, so only the swim latency results have been presented.

All animals were first screened for 2 weeks on a visible platform task in the water maze. Only those animals that were able to learn this visible task were included in the study. Rats were then tested on a hidden platform task for 2 weeks (pretest). The location of the platform was held constant throughout testing on the hidden platform task. Aged animals were designated "impaired" if their mean swim latency on the last $3 \mathrm{~d}$ of testing on the hidden platform task was greater than two standard deviations above the mean swim latency of the young adult rats. Aged rats were designated "unimpaired" if their mean swim latency was less than two standard deviations above the mean swim latency of the young adult rats. The aged impaired animals were equally assigned to a group that would subsequently receive grafts of NGFproducing fibroblasts $(n=6)$, or a control group that would receive noninfected fibroblasts $(n=6)$. Similarly, the young adult animals were equally divided into a group that would subsequently receive grafts of NGF-producing fibroblasts $(n=4)$, control fibroblasts $(n=4)$, or no grafts $(n=6)$. Implantation of the grafts occurred following the end of the pretest. All rats were retested on the hidden platform task 1.5 weeks following the grafting surgery (retest 1) and again 3 weeks following grafting (retest 2).

Spatial probe testing. The day following the last day of the pretest and again following the last day of retest 2 , the platform was removed from the pool, and the rat was given one spatial probe trial. During this trial the rat was allowed to swim for $90 \mathrm{sec}$, and the percentage of the rat's total swim distance that was spent in the correct quadrant of the pool was analyzed. This final trial assessed the accuracy of the animal's place learning.

Histology. The animals were deeply anesthetized and perfused transcardially with $50 \mathrm{ml}$ of $0.1 \mathrm{M}$ phosphate-buffered saline $(\mathrm{pH} \mathrm{7.3)} \mathrm{fol-}$ lowed by $250 \mathrm{ml}$ of $4 \%$ paraformaldehyde. The brains were removed and postfixed overnight in $4 \%$ paraformaldehyde. The brains were then cryoprotected in $30 \%$ phosphate-buffered sucrose for $3 \mathrm{~d}$ at $4^{\circ} \mathrm{C}$. Forty micron thick coronal sections were cut on a freezing microtome and stored in cryoprotectant (glycerol and ethylene glycol in phosphate buffer) at $-20^{\circ} \mathrm{C}$ until histological processing. Every sixth section was stained with cresyl violet, a Nissl stain. Another series of sections were incubatcd $16 \mathrm{hr}$ with a monoclonal antibody (192-IgG) specific for lowaffinity ( $\mathrm{p} 75$ ) NGFr obtained from a hybridoma cell culture supernatant (gift of E. M. Johnson) diluted 1:110 with a mixture of $0.25 \%$ Triton $\mathrm{X}-100$ and $1 \%$ horse serum in $0.1 \mathrm{M}$ TBS. The sections were pretreated with a $0.6 \%$ hydrogen peroxide solution to block endogenous peroxidase prior to incubation with the NGF-r antibody. Following incubation with the NGF-r antibody the sections were then incubated for $1 \mathrm{hr}$ with biotinylated horse anti-mouse IgG (Vector Laboratories) diluted 1:170 with $0.1 \mathrm{M}$ TBS containing $1 \%$ horse serum. The sections were next incubated for $1 \mathrm{hr}$ with an avidin-biotinylated peroxidase complex (using the $\mathrm{ABC}$ Elite Kit, Vector Laboratories) diluted $1: 110$ with $0.1 \mathrm{M}$
TBS containing $1 \%$ horse serum. The stain was visualized by treatment for $12 \mathrm{~min}$ in a $0.05 \%$ solution of $3-3^{\prime}$ diaminobenzidine (DAB), $0.01 \%$ hydrogen peroxide, and $0.04 \%$ nickel chloride in $0.1 \mathrm{M} \mathrm{TBS}$. Immunolabeled sections were mounted onto gelatin-coated glass slides, air dried, dehydrated through a series of alcohols, and coverslipped.

Graft volume. The size of the grafts was measured in the Nissl-stained sections. A computerized image analysis system, the Cue-2 Image Analysis System (Olympus), was used to determine the area of the graft for each section that contained a surviving graft. A magnification of $13.2 \times$ ( $4 \times$ objective with a $3.3 \times$ photo objective) was used for quantification of the areas. The total volume of each graft was then calculated from the area measurements obtained for each section.

Cell number and size. The cells in the nucleus basalis (NBM) were counted and sized in the NGFr-stained sections on the Cue-2 Image Analysis System, using a magnification of $33 \times(10 \times$ objective with a $3.3 \times$ photo objective). The NBM was defined as the area beginning rostrally at the level of the crossing of the anterior commissure and extending caudally to the level of the dorsal hippocampus, including the magnocellular preoptic and peripallidal regions. Immunoreactive cells were defined as cells whose cell body was larger than $80 \mu \mathrm{m}^{2}$; thus, cells that had a smaller area were not included in these analyses. The number of cells in each of $12 \pm 2$ sections per animal was then summed to obtain a total number of cells per side in the NBM for each animal. The mean cell size for all the cells that were counted in the NBM was then obtained for each animal.

In situ hybridization. Sections were mounted on slides and stored at $-70^{\circ} \mathrm{C}$ until the in situ hybridization procedure. ${ }^{35} \mathrm{~S}-\mathrm{Labeled}$ RNA probes were generated as described by Melton et al. (1984). The NGF probe was generated with a 963-bp fragment of mouse NGF (Sma I to PST I, 66 to 1029) cloned into pSP64 as template. Before hybridization, sections were fixed for $30 \mathrm{~min}$ at $4{ }^{\circ} \mathrm{C}$ in $4 \%$ paraformaldehyde, rinsed in $0.5 \% \times \mathrm{SSC}$, and incubated with hybridization buffer without the probe at $42^{\circ} \mathrm{C}$ for $1 \mathrm{hr}$. Hybridization buffer consisted of $50 \%$ formamide, $0.1 \mathrm{M} \mathrm{NaCl}, 20 \mathrm{~mm}$ Tris $(\mathrm{pH} \mathrm{8.0)}$ ) $5 \mathrm{~mm}$ EDTA, $1 \times$ Denhardt's solution, $10 \%$ dextran sulfate, and $10 \mathrm{~mm}$ dithiothreitol. Probes were then added, and hybridization was carried out at $55^{\circ} \mathrm{C}$ overnight. Sections were then rinsed in $2 \times \mathrm{SSC}$ containing $10 \mathrm{mM} \beta$-mercaptoethanol and $1 \mathrm{mM}$ EDTA, and treated for $30 \mathrm{~min}$ with ribonuclease $(20 \mu \mathrm{g} / \mathrm{ml}$ in $0.5 \mathrm{M} \mathrm{NaCl}$ and $10 \mathrm{~mm}$ Tris). Following another rinse, a stringency wash was carried out in $0.1 \times$ SSC containing $10 \mathrm{mM} \beta$-mercaptoethanol and $1 \mathrm{~mm}$ EDTA at $55^{\circ} \mathrm{C}$ for $2 \mathrm{hr}$. Sections were washed in $0.5 \times \mathrm{SSC}$, dehydrated in ethanol containing $0.3 \mathrm{M}$ ammonium acetate, dried, and dipped in emulsion (Amersham).

\section{Results}

Aged and young adult rats were tested in the Morris water maze prior to surgery to assess their spatial memory ability. Threc days following this pretest, NGF-producing primary isologous fibroblasts were stereotaxically injected bilaterally in a region immediately dorsal to the NBM of aged behaviorally impaired and young adult nonimpaired rats. Two additional matched subgroups of aged and young adult rats received control noninfected fibroblast grafts of similar numbers and volumes from the same biopsy with a comparable passage number (Fig. 1A).

One and one-half weeks following surgery, all rats were tested again in the water maze for $3 \mathrm{~d}$ to assess their ability to remember what was learned previously (retest 1 ). The performance of the aged behaviorally impaired rats with control grafts was unchanged compared to the pretest (Fig. $1 B)(p<0.05$, paired $t$ test). Importantly, the performance of the aged group with the NGF-producing grafts was significantly better than the performance of the group that received control grafts $(p<0.05$, onefactor $\Lambda$ NOV $\Lambda$ with post hoc Fisher PLSD). The performance of the aged group that received NGF-producing cell implants was not significantly different from their pretest level $(p>0.10$, paired $t$ test). Surprisingly, the performance of the young adult animals with NGF-producing cell implants was significantly worse than their pretest performance, and the performances of both the young adult group that received control grafts and those 


\section{A. TESTING PARADIGM}
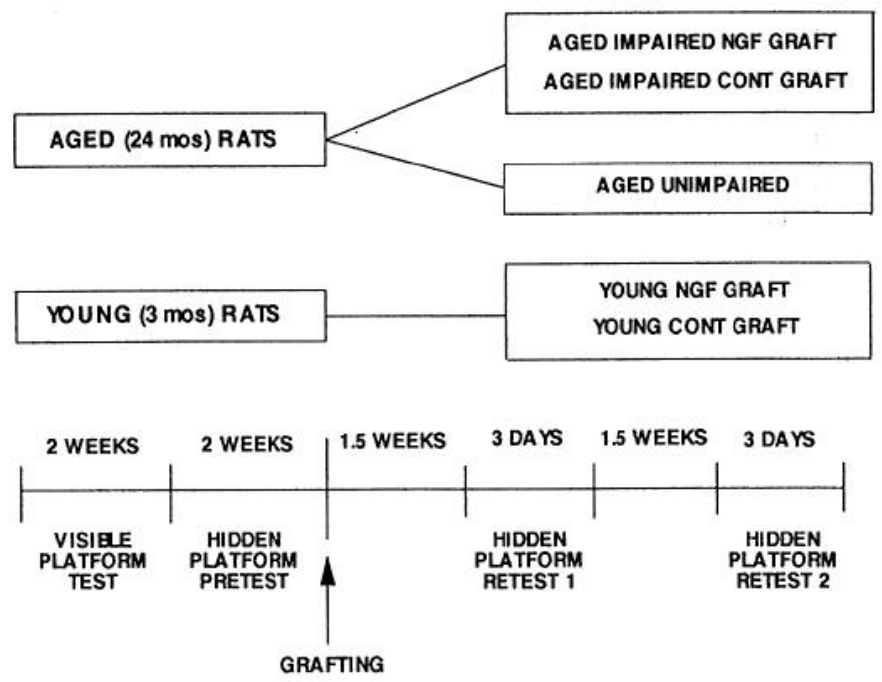

B.

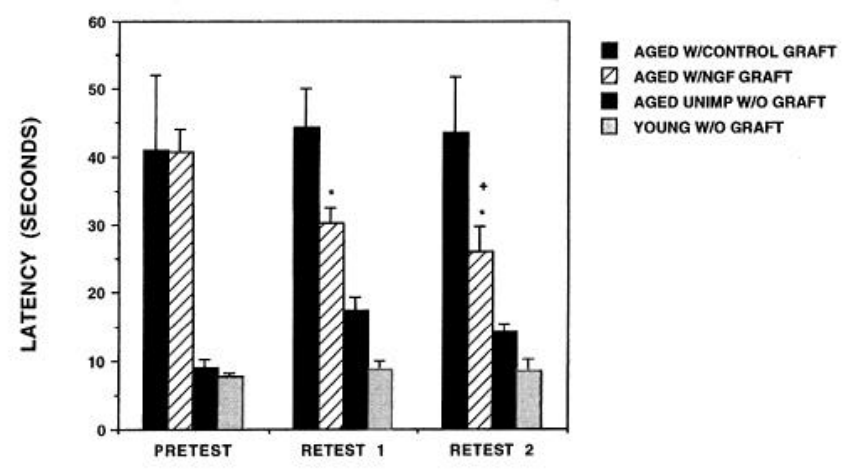

c.

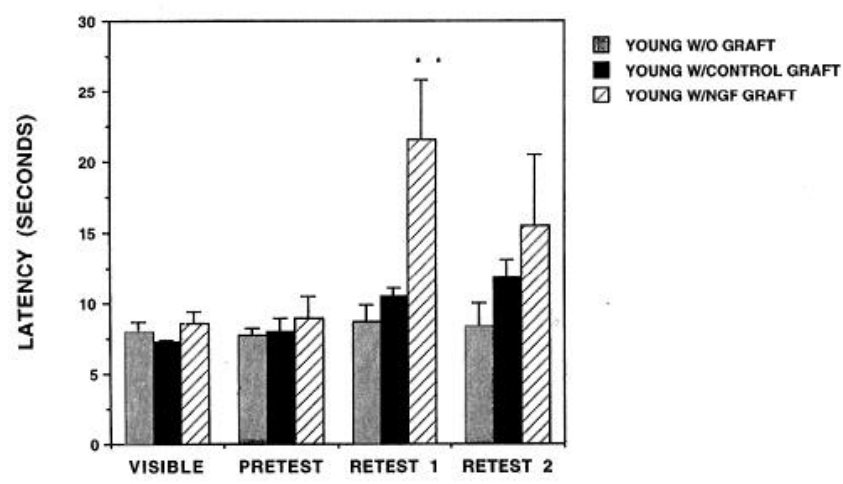

Figure 1. Schematic diagram illustrating the testing paradigm on the water maze task $(A)$, and graphs of the mean latency to find the hidden platform on the last $3 \mathrm{~d}$ of the pretest, all days of retest 1 , and all days of retest 2 on the water maze task for the aged groups $(B)$ and the young adult groups $(C)$. Error bars = SEM. *, significant difference from the aged w/control graft group; + , significant difference from performance on the pretest; $* *$, significant difference from the young adult w/control graft and no graft groups, as well as from performance on the pretest. that did not receive any graft (Fig. $1 C)(p s<0.05$, paired $t$ test and one-factor ANOVA with post hoc Fisher PLSD, respectively).

One and one-half weeks after retest 1 , all animals were tested again for $3 \mathrm{~d}$ (retest 2). Once again, the aged behaviorally impaired rats with NGF grafts performed significantly better than the aged rats with control grafts $(p<0.05$, one-factor ANOVA with post hoc Fisher PLSD), whose performance remained unchanged relative to their pretest performance $(p>0.10$, paired $t$ test). In addition, the performance of the initially impaired aged rats that received NGF-secreting cells was significantly improved compared to their pretest performance $(p<0.05$, paired $t$ test). Furthermore, the aged animals with NGF grafts were no longer significantly worse than the aged unimpaired group $(p>$ 0.10 , one-factor ANOVA with post hoc Fisher PLSD). The young adult group with NGF-producing cell implants had improved compared to their initial impaired performance observed on retest 1 and was no longer significantly different from either the young adult group with control grafts or no grafts. Additionally, their performance did not differ from their pretest performance ( $p s>0.10$, two-factor ANOVA with post hoc Fisher PLSD). The behavioral amelioration observed on the water maze task was not due to an increase in swim speed following grafting. There were no significant differences between swim speed during the pretest, retest 1 , and retest 2 for any group. Nor were there any significant differences in swim speed between the NGF groups versus the control groups ( $p$ s $>0.10$, two-factor ANOVA with post hoc Fisher PLSD).

Spatial probe trials administered following all the pretest trials and once again following all the retest trials demonstrated similar results (Fig. 2A,B). There was a significant difference in spatial acuity, as measured by the spatial probe, between the two aged groups that received grafts compared to both the aged unimpaired and young adult groups ( $p s<0.05$, one-factor ANOVA with post hoc Fisher PLSD), although the two grafted groups were not significantly different from each other on the pretest $(p>0.10)$. On the spatial probe trial following retest 2 , there was a significant difference in spatial acuity between the aged group with NGF-producing grafts compared to the aged group with control grafts $(p<0.05$, one-factor ANOVA with post hoc Fisher PLSD). Additionally, the aged animals with NGF grafts were not significantly impaired compared to the initially unimpaired aged animals $(p>0.10$, one-factor ANOVA with post hoc Fisher PLSD), as well as being significantly improved compared to their pretest performance $(p<0.05$, paired $t$ test). There were no significant differences between any of the young adult groups on either the pretest or the posttest, which was administered after the young adult animals that received NGF-producing grafts had recovered from their transient behavioral deficits ( $p s>0.10$, one-factor ANOVA with post hoc Fisher PLSD).

All rats were perfused following retest 2 and their brains were sectioned. To assess whether the NGF transgene continued to be expressed within the implanted fibroblasts, sections through the grafts were processed for in situ hybridization to NGF mRNA. Positive hybridization for NGF was only found to be present over fibroblasts in the NGF-producing graft (Fig. 3).

A series of sections was stained for low-affinity NGF receptor (p75) immunocytochemistry. Immunohistochemical staining for low-affinity NGF receptor colocalizes with staining for cholineacetyltransferase in greater than $90 \%$ of cells in the basal forebrain region and, thus, is a good marker for NGF responsive 
A.

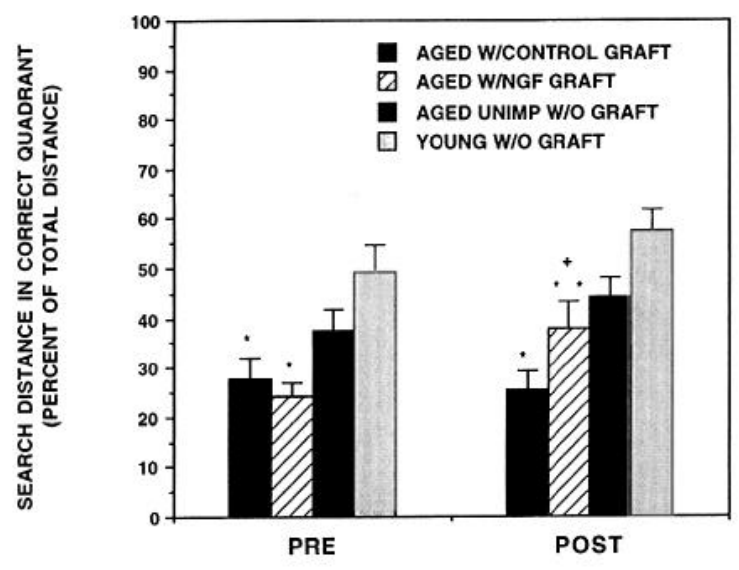

B.

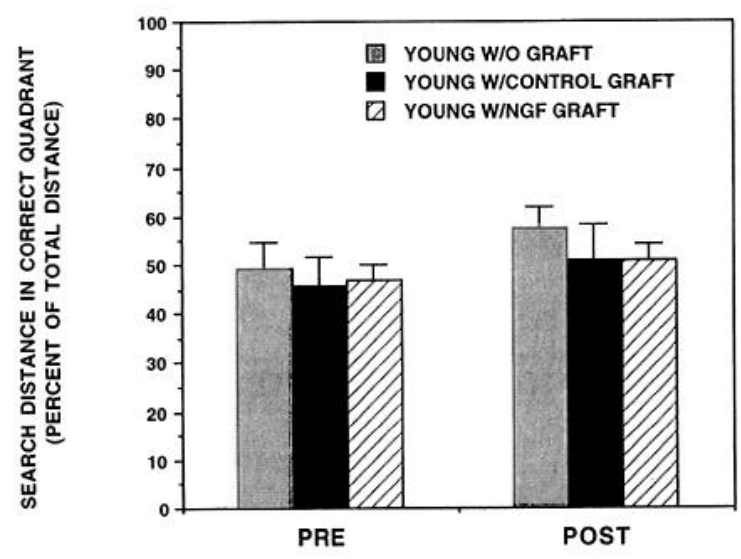

Figure 2. Graphs of the percentage of total swim distance that was spent in the quadrant that previously contained the platform during probe trials following the final day of testing on the pretest and following the final day of testing on retest 2 for the aged groups $(A)$ and the young adult groups $(B)$. Error bars = SEM. *, significant difference from the aged unimpaired group and the young adult groups; +, significant difference from the aged w/control graft group; **, significant difference from performance on the pretest.

cholinergic neurons in this region (Kawaja et al., 1992). The grafts were easily detected, and their volumes were calculated. NGF receptor-immunoreactive neurons were sized and counted in sections throughout the basal forebrain of all animals tested.

No significant morphological differences were observed between the left and right sides of the brain within any group, so statistics were calculated based on the mean size and number for both sides for each animal. Aged rats with NGF-producing grafts had significantly more NGF receptor-positive NBM neurons than aged rats that received control grafts (Table 1, Fig. 4). There was a trend for larger NGFr-positive cells in both the aged and young adult rats that received NGF grafts compared to their respective control groups that received non-NGF-producing cells (Table 1, Fig. 4). NGF receptor-positive processes were observed throughout the NGF-producing cell grafts of both young adult and aged rats, but staining was more robust in the young grafts (Fig. 4C,D). No NGF receptor-positive processes were observed in the control grafts implanted in either young or aged rats (Fig. 4E,F).

\section{Discussion}

Discrete local administration of NGF to cells in the NBM was able to ameliorate behavioral deficits in aged animals, but resulted in transient behavioral deficits in young adult animals. The memory improvement observed in the aged rats with NGFproducing cell implants was greater than that observed in our previous experiments that demonstrated that unilateral intraventricular infusion of purified NGF resulted in retention of spatial memory in aged rats (Fischer et al., 1987, 1991). In the current work, a statistically significant memory improvement was observed between the pretest and retest 2 . We attribute the greater performance improvement to bilateral delivery of the NGF, and the local delivery of NGF directly to the response cells. Furthermore, these results support our previous observation that ICV NGF has its greatest effects on the NBM (Fischer et al., $1987,1991)$, and that NGF-producing grafts to the NBM of excitotoxic lesioned animals improve behavioral performance in the same task (Dekker et al., 1994). These results demonstrate that the NBM-cortical system is important for learning and memory function, and neurotrophic therapy targeted at NBM cholinergic cells can ameliorate age-related memory deficits.

The finding of a transient impairment in the young adult animals with NGF-producing cell grafts was similar to that observed by Markowska et al. (1994), and suggests that cholinergic activity requires a balance between hypo- and hyperfunction. The NGF-producing grafts did induce aberrant sprouting of cholinergic fibers into the grafts, which may result in decreased cholinergic fiber density in the normal target regions in the cortex. Studies have shown that cholinergic neurons will retract fibers from areas of lower NGF concentration to areas of higher NGF concentration (Ma et al., 1992). Further studies will evaluate this possibility. In the study by Markowska et al. (1994) the NGF was delivered intraventricularly, and no morphological data was presented to determine if the NGF induced local changes in the choline responsive neurons. Williams (1991) has reported that high concentrations of NGF delivered intracerebroventricularly result in hypophagia, but we did not observe or measure any loss of weight in our animals through the course of the experiment. Other evidence for the potential deleterious effect of NGF have been reported by Pallage et al. (1986), where they found that following septal lesions, NGF infusion induced and enhanced behavioral deficit on maze learning, but the timing of the induced deficit and the anatomical or physiological correlates of the deficit were not explored and not replicated by the same authors in later studies (Pallage et al., 1992). Thus, further studies will be needed to explore the limits and mechanism of the induced dysfunction in the young adult animals. We have only assessed cholinergic function indirectly by quantifying the size and number of p75-positive neurons; direct measurements of cholinergic function such as measures of high-affinity choline uptake or acetylcholine turnover would provide a more direct measure of cholinergic function. However, both this present study and the study by Markowska et al. (1994) suggest that NGF may have a deleterious effect in normal young animals, and one should be cautious in using NGF in normal young animals.

The recovery of the young adult rats to their previous performance level on retest 2 may be due to strategies and/or mechanisms that allow the animals to compensate for increased interference that may result from increased amounts of NGF. Alternatively, the recovery could be caused by a decrease in 
YOUNG/NGF YOUNG/CONTROL
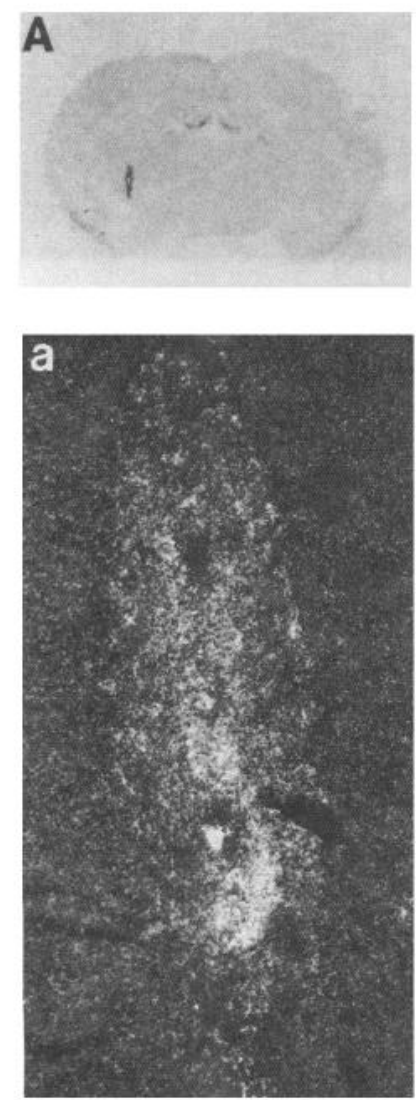

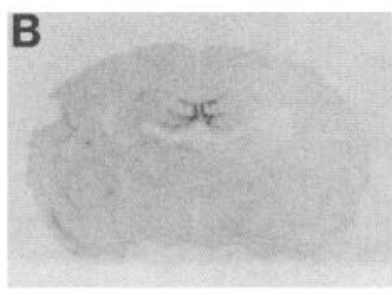

6.

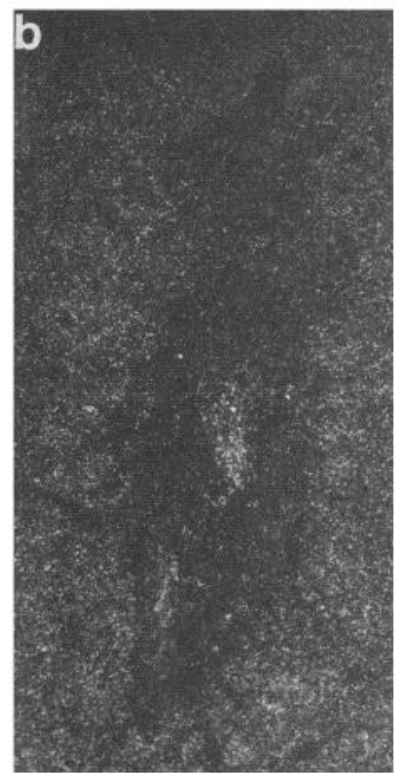

AGED/NGF

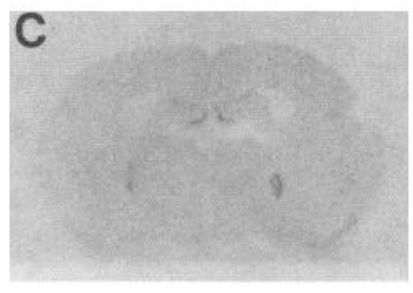

\section{C}

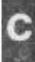

AGED/CONTROL

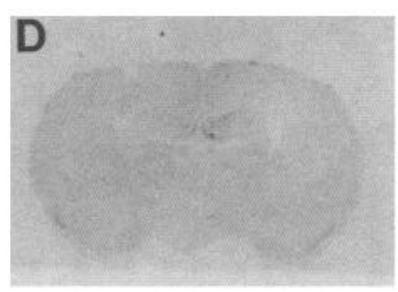

d

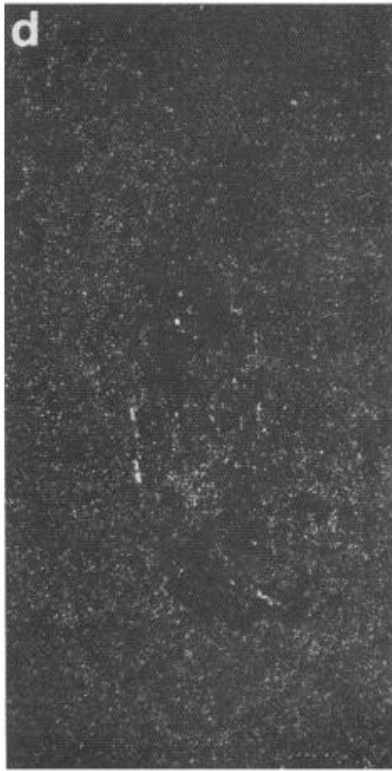

Figure 3. A and $a$, Photomicrograph of low-power direct images of exposed autoradiographs $(A)$ and high power of developed sections in NGFproducing graft in a young animal $(a) . B$ and $b$, Control graft in a young animal. $C$ and $c$, NGF-producing graft in an aged animal. $D$ and $d$, Control graft in an aged animal.

NGF secretion resulting from partial fibroblast cell loss that occurs in the first 3 weeks (Kawaja et al., 1992). However, the aged animals with NGF-producing grafts remained significantly improved on retest 2 , and relative to the aged rats with control grafts, suggesting that either adequate amounts of NGF continue to be produced to maintain performance, or NGF is only required acutely to induce lasting behavioral improvement, as has been seen in fimbria-fornix lesioned animals (M. H. Tuszynski and F. H. Gage, manuscript submitted). Most importantly, in this study we show that NGF mRNA is expressed through the du- ration of the experiment. Previous studies have demonstrated that genetically modified fibroblast grafts can survive for periods of up to 6 months and continue to express the gene of interest for at least 10 weeks (Fisher et al., 1991; Kawaja et al., 1992), but this present study links expression to function.

The observed increase in number of low-affinity NGFr-positive cells in the aged rats with NGF grafts relative to aged rats with control grafts was probably not the result of an actual increase in cell number, but rather an increase in the expression of NGF receptors which leads to increased immunoreactivity

\section{Table 1. Number and size of low-affinity NGFr-positive cells in the host NBM and volume of the} grafts

\begin{tabular}{llll} 
Groups & $\begin{array}{l}\text { Number of } \\
\text { NGFr-positive } \\
\text { cells }\end{array}$ & $\begin{array}{l}\text { Size of } \\
\text { NGFr-positive } \\
\text { cells }\left(\mu \mathrm{m}^{2}\right)\end{array}$ & $\begin{array}{l}\text { Graft } \\
\text { volume }\left(\mathrm{mm}^{3}\right)\end{array}$ \\
\hline Aged w/NGF grafts & $918 \pm 29 *$ & $181 \pm 5$ & $0.550 \pm 0.087$ \\
Aged w/control grafts & $794 \pm 44 * B \ddagger$ & $167 \pm 7 \S$ & $0.586 \pm 0.091$ \\
Aged unimpaired & $888 \pm 32$ & $170 \pm 9$ & \\
Young nongrafted & $957 \pm 37 \dagger$ & $177 \pm 8$ & $0.589 \pm 0.040$ \\
Young w/NGF grafts & $942 \pm 37 \ddagger$ & $193 \pm 12 \S$ & $0.572 \pm 0.057$ \\
Young w/control grafts & $937 \pm 60$ & $172 \pm 6$ & \\
\hline
\end{tabular}

$*, \dagger, \ddagger$, and $\S$ denote significant differences between similarly labeled groups $(p<0.05$, one-factor ANOVA with post hoc Fisher PLSD). 

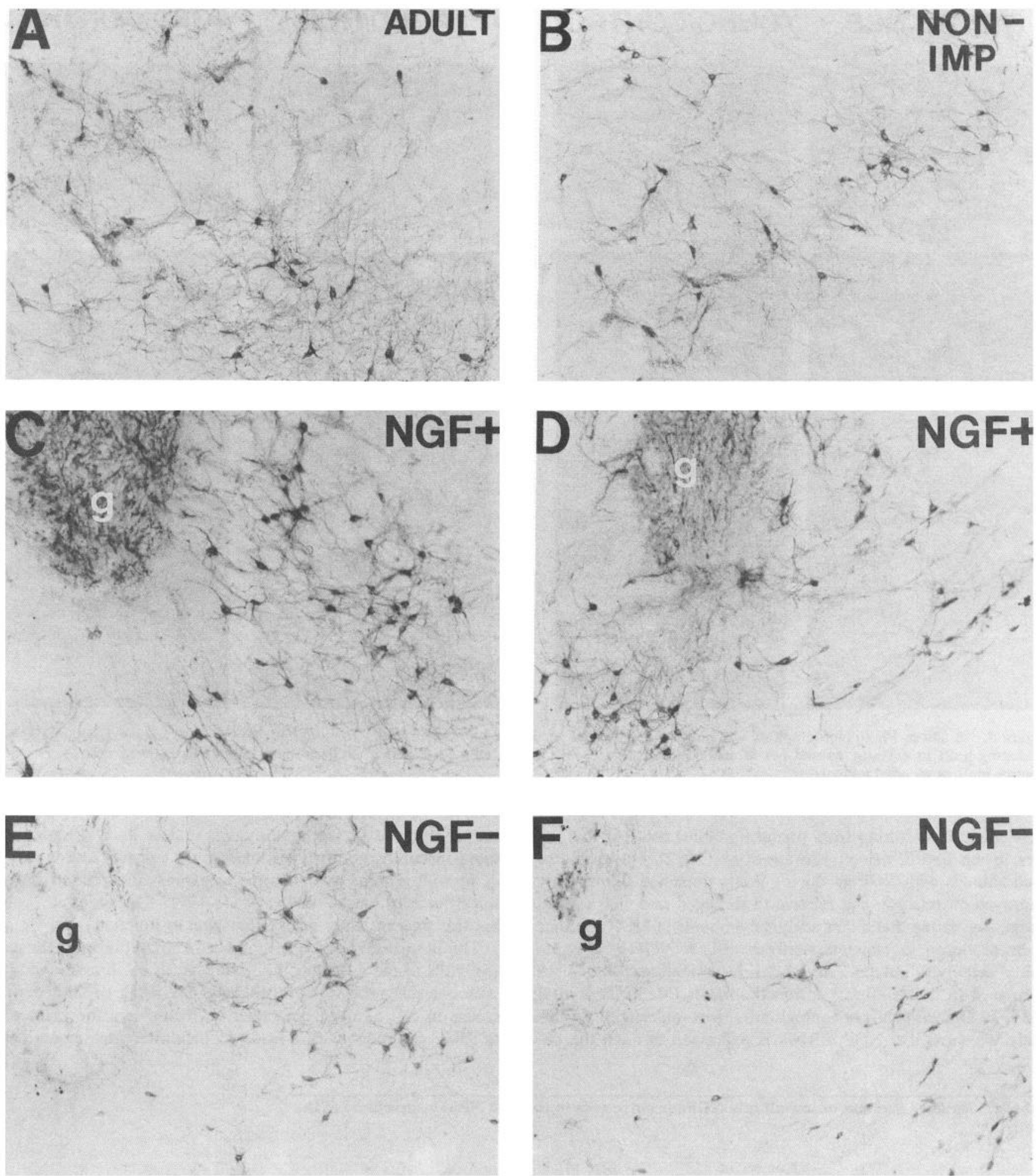

Figure 4. Photomicrograph of the nucleus basalis region of a young adult animal without a graft $(A)$, an aged nonimpaired animal $(B)$, a young adult animal that received a graft $(g)$ of NGF-producing fibroblasts $(C)$, an aged-impaired animal that received a graft $(g)$ of NGF-producing fibroblasts $(D)$, a young adult animal that received a graft $(g)$ of control fibroblasts $(E)$, and an aged impaired animal that received a graft $(g)$ of control fibroblasts stained for NGF receptor $(F)$. Magnification, $90 \times$.

and detectability (Gage et al., 1989; Higgins et al., 1989). The comparable survival volume of the grafts in young adult and aged rats suggests that, unlike in neuronal grafts, host age is not a factor in fibroblast graft survival. In contrast, the ability of the host to innervate the graft may be dependent upon host age, as demonstrated by more robust NGFr-positive staining of processes in the grafts within the young adult animals. Thus, either the aged host cells were less responsive to NGF or the NGF- 
producing implants produced less NGF in the aged brain. Future studies are being designed to investigate these two possibilities.

We conclude that local delivery of NGF to the NBM of aged, cognitively impaired rats results in a significant improvement in learning and memory, and an increase in the size and number of NGF responsive cells in the NBM. Further, we show that NGF results in a transient behavioral impairment in young nonimpaired rats, suggesting that cholinergic hyperfunction, just as cholinergic hypofunction results in cognitive dysfunction.

\section{References}

Arenas E, Perrson H (1994) Neurotrophin-3 prevents the death of adult central noradrenergic neurons in vivo. Nature 367:368-371.

Batchelor PE, Armstrong DM, Blaker SN, Gage FH (1989) Nerve growth factor receptor and choline acetyltransferase colocalization in neurons within the rat forebrain: response to fimbria-fornix transection. J Comp Neurol 284:187-204.

Dekker AJ, Fagan AM, Gage FH, Thal LJ (1994) Effects of brainderived neurotrophic factor and nerve growth factor on remaining neurons in the lesioned nucleus basalis magnocellularis. Brain Res 639:149-155.

Fischer W, Wictorin K, Bjorklund A, Williams LR, Varon S, Gage FH (1987) Amelioration of cholinergic neuron atrophy and spatial memory impairment in aged rats by nerve growth factor. Nature 329:6568.

Fischer W, Bjorklund A, Chen K, Gage FH (1991) NGF improves spatial memory in aged rodents as a function of age. J Neurosci 11: 1889-1906.

Fisher LJ, Jinnah HA, Kale LC, Higgins GA, Gage FH (1991) Primary fibroblasts genetically modified to produce L-dopa. Neuron 6:371380.

Gage FH, Batchelor P, Chen KS, Chin D, Higgins GA, Koh S, Deputy S, Rosenberg M. Fischer W, Bjorklund A (1989) NGF receptor reexpression and NGF mediated cholinergic neuronal hypertrophy in the damaged adult neostriatum. Neuron 2:1177-1184.

Gage FH, Kawaja MD, Fisher LJ (1991) Genetically modified cells: applications for intracerebral grafting. Trends Neurosci 14:328-333.

Higgins GA, Koh S, Chen KS, Gage FH (1989) Nerve growth factor (NGF) induction of NGF receptor gene expression and cholinergic neuronal hypertrophy within the basal forebrain of the adult rat. Neuron 3:247-256.

Kawaja MD, Gage FH (1992) Morphological and neurochemical features of cultured primary skin fibroblasts of Fischer 344 rats following striatal implantation. J Comp Neurol 317:102-116.
Kawaja MD Rosenherg MB, Yoshida K, Gage FH (1992) Somatic gene transfer of nerve growth factor promotes the survival of axotomized septal neurons and the regeneration of their axons in adult rats. J Neurosci 12:2849-2864.

Ma Y, Campenot RB, Miller FD (1992) Concentration-dependent regulation of neuronal gene expression by nerve growth factor. $\mathbf{J}$ Cell Biol 117:135-141.

Markowska AL, Koliatsos VE, Breckler SJ, Price DL, Olton DS (1994) Human nerve growth factor improves spatial memory in aged but not in young rats. $\mathrm{J}$ Neurosci $14: 4815-4824$.

Melton DA, Krieg PA, Rebagliati MR, Maniatis T, Zinn K, Green MR (1984) Efficient in vitro synthesis of biologically active RNA and RNA hybridization probes from plasmids containing a bacteriophage SP6 promoter. Nucleic Acids Res 12:7035-7056.

Pallage V, Toniolo G, Will B, Hefti F (1986) Long-term effects of nerve growth factor and neural transplants on behavior of rats with medial septal lesions. Brain Res 386:197-208.

Pallage V, Orenstein D, Will B (1992) Nerve growth factor and septal grafts: a study of behavioral recovery following partial damage to the septum in rats. Behav Brain Res 47:1-12.

Rosenberg MB, Friedmann T, Robertson RC, Tuszynski M, Wolff JA, Breakefield XO, Gage FH (1988) Grafting of genetically modified cells to the damaged brain: restorative effects of NGF gene expression. Science 242:1575-1578.

Schinstine M, Rosenberg MB, Routledge-Ward C, Friedmann T, Gage FH (1992) Effects of choline and quiescence on Drosophila choline acetyltransferase expression and acetylcholine production by transduced rat fibroblasts. J Neurochem 58:2019-2029.

Sendtner M, Schmalbruch H, Stockli KA, Carroll P, Kreutzberg GW, Thoenen $\mathrm{H}$ (1992) Ciliary neurotrophic factor prevents degeneration of motor neurons in mouse mutant progressive motor neuronopathy. Nature 358:502-504.

Stromberg I, Wetmore CJ, Ebendal T, Ernfors P, Persson H, Olson L (1990) Rescue of basal forebrain cholinergic neurons after implantation of genetically modified cells producing recombinant NGF. $J$ Neurosci Res 25:405-411.

Whittemore SR, Holets VR, Keane RW, Levy DJ, McKay RD (1991) Transplantation of a temperature-sensitive, nerve growth factor-secreting, neuroblastoma cell line into adult rats with fimbria-fornix lesions rescues cholinergic septal neurons. J Neurosci Res 28:156170.

Williams LR (1991a) Hypophagia is induced by intracerebroventricular administration of nerve growth factor. Exp Neurol 113:31-37.

Williams LR (1991b) Exogenous nerve growth factor stimulates choline acetyltransferase activity in aging Fischer 344 male rats. Neurobiol Aging 12:39-46.

Williams LR, Rylett RJ, Moises HC, Tang AH (1991) Exogenous NGF affects cholinergic transmitter function and $\mathrm{Y}$-maze behavior in aged Fischer 344 male rats. Can J Neurol Sci 18:403-407. 